\title{
Hierarchical electrospun nanofibers treated by solvent vapor annealing as air filtration mat for high-efficiency PM2.5 capture
}

\author{
Xinxin Huang ${ }^{1,2}$, Tifeng Jiao ${ }^{1,2^{*}}$, Qingqing $\mathrm{Liu}^{2}$, Lexin Zhang ${ }^{2}$, Jingxin Zhou ${ }^{2}$, Bingbing $\mathrm{Li}^{3}$ and \\ Qiuming Peng ${ }^{1 *}$
}

\begin{abstract}
Recently, air pollution has become more serious and started to have a dramatic effect on the health of humans in many large cities. Generally, outdoor personal protection, such as commercial masks, cannot effectively prevent the inhalation of many pollutants. Particulate matter (PM) pollutants are a particularly serious threat to human health. Here we introduce a new efficient air filtration mat that can be used for outdoor protection. The new efficient air filter's nanocomposite materials were successfully fabricated from poly $(\varepsilon-$ caprolactone)/polyethylene oxide (PCL/PEO) using an electrospinning technique and solvent vapor annealing (SVA). SVA treatment endows the wrinkled fiber surface and enhances the PM2.5 capture capacity of protective masks. This nanowrinkled air filtration mat can effectively filter PM2.5 with a removal efficiency of $\mathbf{8 0 . 0 1 \%}$ under seriously polluted conditions (PM2.5 particle concentration above $225 \mathrm{mg} \mathrm{m}^{-3}$ ). Our field test in Qinhuangdao indicated that the air filtration mat had a high PM2.5 removal efficiency under thick haze. Compared to commercial masks, the fabricated SVA-treated PCL/PEO air filter mat demonstrated a simpler and ecofriendly preparation process with excellent degradation characteristics, showing wide potential applications with a high filtration efficiency.
\end{abstract}

Keywords: electrospinning nanofiber mat, solvent vapor annealing, air filtration, PM2.5 removal

\section{INTRODUCTION}

In the last several years, environmental issues have drawn extensive attention owing to the dangerous nature of their impact on human health and the environment [1-4]. Particulate matter $(\mathrm{PM})$ is a very complex mixture of pollutants with extremely fine particles and small liquid droplets [5-8]. PM2.5 is particularly harmful because these small particles can penetrate the lungs and the bronchi [9-13]. In indoor environments, these particles can be filtered out by ventilation or central air-conditioning systems, whereas the individual protection used by people outdoors is not effective because the PM2.5 removal efficiency of most commercial masks is low because of the micro-sized diameter of the particles. Thus, the efficient and convenient removal of these PM pollutants from the air has become an urgent and challenging concern for researchers [14]. For instance, the design and development of efficient filtration materials that can remove PM2.5 particles with high recyclability are a central focus. It is well documented that filtration fibers with high porosity, high accumulated density, and small fiber diameters exhibit a higher PM2.5 removal efficiency [15].

It is well known that electrospinning is a relatively simple method of producing continuous fibers with nano- and submicron-sized diameters [16]. The fibers prepared by electrospinning exhibit high porosity, fine pore size, staggered pore structure, small pore size, and controllable diverse architecture and thickness, which makes them ideal candidates for air filtration materials [17-20]. Based on these properties, many types of electrospun fibrous membranes, including polyurethane (PU), polystyrene, polyvinyl alcohol, polyvinyl acetate, Nylon 6 nanofibers, and polyacrylonitrile (PAN) nanofibers, have been successfully fabricated and used as air filtration media [21-27]. However, these nanofibers usually have low breathability and low recyclability. Cui

\footnotetext{
${ }^{1}$ State Key Laboratory of Metastable Materials Science and Technology, Yanshan University, Qinhuangdao 066004, China

${ }^{2}$ Hebei Key Laboratory of Applied Chemistry, School of Environmental and Chemical Engineering, Yanshan University, Qinhuangdao 066004, China

${ }^{3}$ Department of Chemistry, Science of Advanced Materials Doctoral Program, Central Michigan University, Mount Pleasant, MI 48859, USA

* Corresponding authors (emails: tfjiao@ysu.edu.cn (Jiao T); pengqiuming@ysu.edu.cn (Peng Q))
} 
et al. [15] reported on a transparent air filter prepared by electrospinning with high-efficiency $\mathrm{PM}_{2.5}$ capture. Pan et al. [28] designed and prepared porous bead-on-string polylactic acid (PLA) fibrous mat-type materials by electrospinning for PM filtration. Some research has illustrated that the morphological characteristics of fibers have a significant impact on the fibers' filtration performance, such as their diameter, surface structure, packing density, and volume fraction [29-31]. The abovementioned nanofibers are generally composed of single elements with mostly smooth surface structures, circular cross sections, and very small diameters, which is beneficial for efficiently capturing PM2.5 [32-34]. However, multicomponent polymer nanofibers generally show stronger controllability than single-component polymer nanofibers in terms of strength, recyclability, and specific surface area [35]. For example, PAN, polyvinyl chloride (PVC), PU, polyethylene terephthalate nanofiber membranes enabled with PU, fly ash particles, and cyclodextrin, respectively, improved the mechanical properties primarily because of various intermolecular weak interactions [22,36-38]. At the same time, nanofibers exhibited high filtration efficiency and were found to be potentially suitable for the removal of certain air pollutants, along with biological contaminants owing to their high specific surface area [39]. Thus, multicomponent polymers are preferred in electrospinning to prepare air filter mats owing to their excellent chemical and thermal stability of synthetic polymers along with controllable fluid properties and surface structure. Researchers often focused on the key point of improving the air filtration efficiency by adjusting the thickness of the nanofibers and neglected the more important key point of regulating the surface structure of nanofibers $[40,41]$.

In order to overcome the challenges that were previously described, we designed and successfully prepared electrospun $\operatorname{poly}(\varepsilon$-caprolactone)/polyethylene oxide (named PCL/PEO) nanofiber mat composite membrane materials, which were then treated with solvent vapor annealing (SVA) to form nanowrinkled nanostructures to remove PM2.5. The selection of the particular PCL/PEO material used in this study was based on several considerations. First, PCL can interact with acetone solvents and its presence is a prerequisite for the preparation of wrinkled structures in PCL/PEO fibers. Secondly, PCL is an ecofriendly and inexpensive material that is easy to obtain. In this study, the motivation behind SVA treatment of electrospun mats originated primarily from the modification and regulation of micro/nanos- tructures of membranes for potential incremental improvement of filter efficiency. In the current SVA process that is used to fabricate PCL/PEO materials, acetone, as a poor solvent for PCL/PEO nanofibers, can delocalize the amorphous chains very efficiently and allow them to be redeposited onto the preexisting crystal edges, growing nanowrinkled nanostructures on the surface of the PCL/ PEO nanofibers [42-45]. The fabricated SVA-treated air filtration mat demonstrated a high PM2.5 removal efficiency due to nanowrinkled nanostructures, low resistance to air flow, and light weight. The PM2.5 removal efficiency of the nanofiber mat reached $80.01 \%$ by adjusting the surface structure and fiber thickness, and the PM2.5 removal efficiency of commercial masks was thus increased from $7 \%$ to nearly $80 \%$ under extremely hazardous air quality conditions.

\section{EXPERIMENTAL SECTION}

\section{Materials}

The experimental materials, PCL $\left(M_{\mathrm{n}}=80 \mathrm{~kg} \mathrm{~mol}^{-1}\right.$; Sigma-Aldrich (Shanghai) Trading Co. Ltd.), PEO $\left(M_{\mathrm{n}}=\right.$ $600 \mathrm{~kg} \mathrm{~mol}^{-1}$; Sigma-Aldrich (Shanghai) Trading Co. Ltd.), trichloromethane (analytical reagent grade; Fisher Scientific, Waltham), and acetone (analytical reagent grade; Fisher Scientific), were used directly without further purification.

\section{Nanocomposites fabrication}

PCL/PEO nanofiber mats were fabricated via an improved electrospinning method. In brief, $0.21 \mathrm{~g}$ of PEO powder and $0.5 \mathrm{~g}$ of PCL pellets were dissolved in $6.3 \mathrm{~mL}$ of chloroform solution and then stirred for $24 \mathrm{~h}$ at room temperature to obtain a uniform and transparent spinning precursor solution [45]. Next, the solution was allowed to stand for $1 \mathrm{~h}$ to drive the air bubbles out of the solution. After that, the uniform solution was transferred into a syringe. We chose three typical electrospun fiber samples with the following parameters (needle tip voltage, working distance, feed rate of solutions): $25 \mathrm{kV}, 25 \mathrm{~cm}$, $0.3 \mathrm{~mL} \mathrm{~h}^{-1}$ (Sample 1), $15 \mathrm{kV}, 25 \mathrm{~cm}, 1 \mathrm{~mL} \mathrm{~h}^{-1}$ (Sample 2), and $15 \mathrm{kV}, 15 \mathrm{~cm}, 1 \mathrm{~mL} \mathrm{~h}^{-1}$ (Sample 3). The environmental parameters included humidity of $18 \%$ and a temperature of $15^{\circ} \mathrm{C}$ during the electrospinning process. About $300 \mathrm{~mL}$ of acetone was poured into a $5 \mathrm{~L}$ desiccator, which was maintained at a constant temperature of $22-23^{\circ} \mathrm{C}$. The samples were put on a ceramic plate inside the desiccator and fumigated in $100 \%$ acetone vapor [46-48]. At the same time, the samples were fumigated in acetone vapor inside the desiccator for 5 
days. After 5 days, the samples were taken out of the desiccator, dried under vacuum for $24 \mathrm{~h}$ at room temperature, and evaluated for further characterization.

\section{Batch filter tests for PM2.5 removal}

For the filtration experiment, the filter properties of the fabricated nanocomposite materials were investigated, especially the PM2.5 removal efficiency. In order to find the most efficient air filter materials, commercial masks made of different materials and electrospun fiber mat samples from different production methods were investigated for PM2.5 capture at room temperature. In this study, PM2.5 was generated by burning moxa stick incense for a period of time in a confined room. The burning smoke contained PM2.5 above $270 \mu \mathrm{g} \mathrm{m}^{-3}$, and the smoke had a very complex composition that included $\mathrm{CO}, \mathrm{CO}_{2}$, and certain volatile organic compounds, such as benzene, alcohols, amines, phenols, and long-chain hydrocarbons [49-53]. This smoke had a composition similar to that of common haze, so it can be used as a model to simulate haze in the laboratory [54,55]. The current environmental PM2.5 concentration was recorded, and then the nanofiber mat was fixed with a rubber band on the PM2.5 mask filtration efficiency measuring device, with count data collected every $5 \mathrm{~s}$ with a total test time of $90 \mathrm{~s}$. To ensure the accuracy of the results, each sample was tested 5 times and averaged. For other parameters of the fiber mats and commercial masks of different materials, similar experimental procedures were adopted. The change in PM2.5 concentrations was evaluated by measuring the PM2.5 mask filtration efficiency (Inovafitness Electronic Technology Co., Ltd.) at room temperature using an air flow of $600 \mathrm{~L} \mathrm{~min}^{-1}$. For the recycling experiments, the filtered fiber mats were washed thoroughly with deionized water and ethanol 4-5 times and were found to maintain a relatively high filtering efficiency [56].

\section{Characterization}

The microstructure of all the obtained composite materials was characterized using field-emission scanning electron microscopy (FE-SEM; Hitachi S-4800-II) with 5$15 \mathrm{kV}$ accelerating voltage and transmission electron microscopy (TEM; Hitachi HT7700, High-Technologies Corp.). X-ray photoelectron spectroscopy (XPS) was performed with a Thermo Fisher Scientific ESCALab 250Xi with an $\mathrm{Al}-\mathrm{Ka}$ source, and X-ray diffraction (XRD) characterization was accomplished with an X-ray diffractometer equipped with a $\mathrm{CuKa} \mathrm{X}$-ray radiation source and a Bragg diffraction setup (SmartLab, Rigaku). The thermal stability of the samples was measured on a simultaneous thermal analyzer using thermogravimetrydifferential scanning calorimetry (TG-DSC) in a nitrogen atmosphere (Netzsch STA 409 PC Luxx, Germany). The change in particle concentration was measured using a PM2.5 mask filtration efficiency measuring device (Inovafitness Electronic Technology Co., Ltd.).

\section{RESULTS AND DISCUSSION}

\section{Structural characterization of the air filtration mats}

Fig. 1 presents the steps of the entire experimental procedure, including the preparation of the precursor solutions, the electrospinning process, the SVA treatment, and the final PM2.5 removal test. Simply stated, the PCL/ PEO nanofibers were obtained by electrospinning, and the surface of the fibers was wrinkled by SVA treatment. Finally, the treated fibers were subjected to PM2.5 filtration experiments. The morphologies and nanostructures of all the prepared composite materials before and after SVA treatment were investigated using SEM.

A typical SEM image of the nanowrinkled air filtration mat fabricated from a PCL/PEO chloroform solution is presented in Fig. 2, which is similar to examples from previous reports $[57,58]$. The image in Fig. 2a distinctly demonstrates that the electrospun mat shows a uniform and smooth fiber with a fiber diameter distribution concentrated at $1-1.5 \mu \mathrm{m}$ (Fig. 2a'). The fibers' surface exhibits uniform wrinkled nanostructures (Fig. 2b) with an increased specific surface area when the electrospun fiber mat was treated via the SVA method [59-61]. Additionally, the diameter of the SVA-treated fibers shows the range of 3-5 $\mu \mathrm{m}$ (Fig. 2b'), indicating that the nanostructures of the fibers changed clearly with the SVA-treated process.

Electrospinning liquid jets generate considerable stretching forces on nanofibers of about $2 \mu \mathrm{m}$ diameter, which consist of dislocated sheets and loose amorphous chains. The primary PCL/PEO fibers were dried at $25^{\circ} \mathrm{C}$ for $24 \mathrm{~h}$ under vacuum and then aged at $20-25^{\circ} \mathrm{C}$ for $48 \mathrm{~h}$ prior to the SVA test. The used aged temperature must be lower than the PCL/PEO crystallization temperature to keep organized fiber nanostructures; thus, the primary fibers were aged at $20-25^{\circ} \mathrm{C}$ for further crystallization [62-64]. The PCL/PEO fibers that were SVA-treated exhibited clear lamella-like petals. The acetone vapor appeared to first selectively diffuse into the amorphous region because the chain packing in the crystallization zone was loose in the amorphous region, and many lamella-like petals grew on the annealed PCL/PEO 


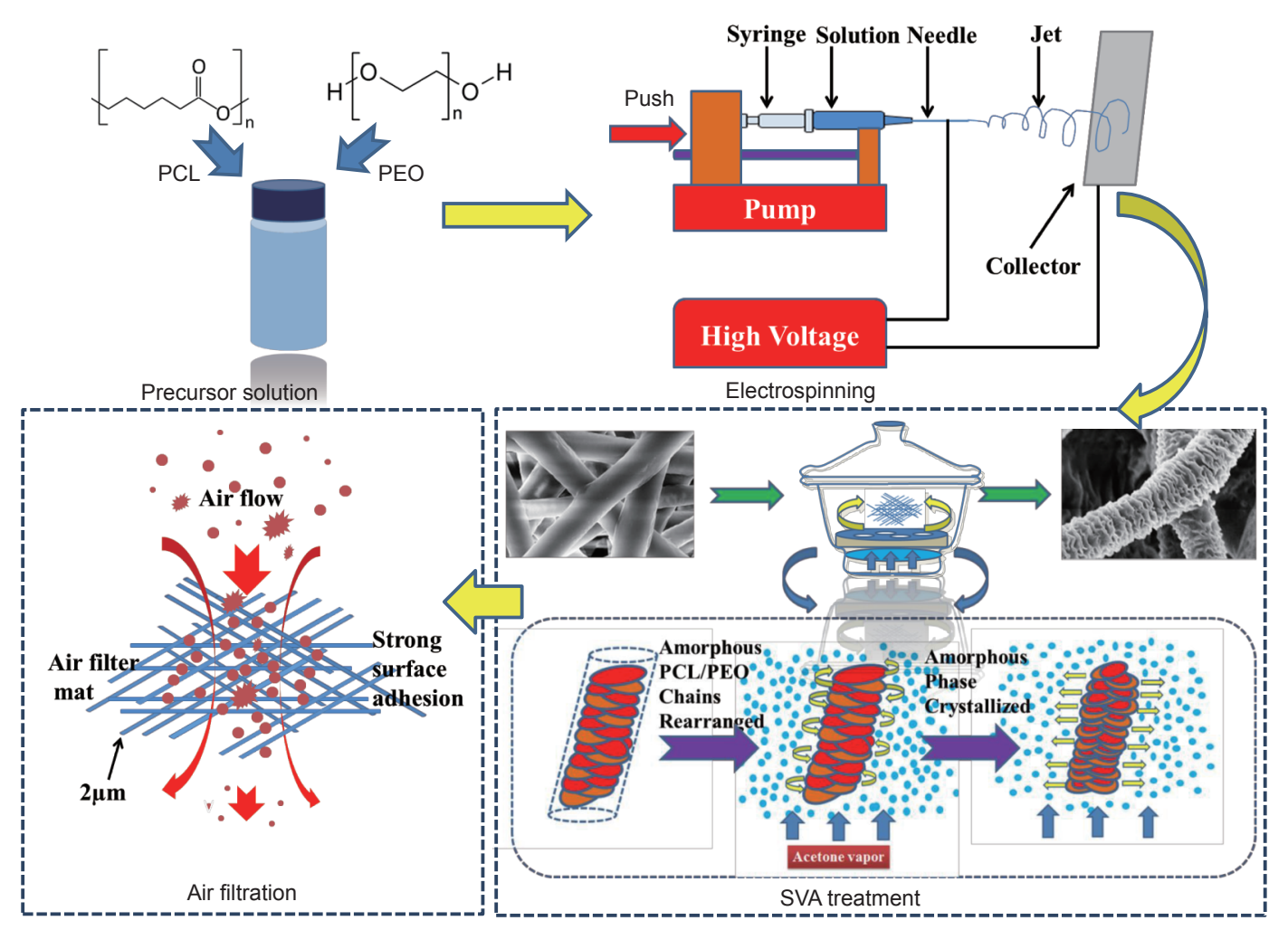

Figure 1 A schematic illustration of the preparation and filtration of the obtained electrospun nanowrinkled air filtration mat.

nanofibers due to those amorphous chains with low availability and low mobility, which can cause rearrangement during annealing [45]. First, the acetone vapor selectively mobilized kinetically stagnant amorphous chains as the liquid jet quickly dried. Then, these amorphous chains crystallized at the edges of preexisting crystals with the action of acetone. Finally, a wrinkled structure with a high density grew on the fiber surface.

SVA processing time and temperature were found to be extremely important factors affecting fiber morphology. SEM images of the PCL/PEO fibers were obtained for different SVA treatment durations at room temperature in ceramic desiccators. Images of Sample 1 dried for $24 \mathrm{~h}$ under vacuum and aged $48 \mathrm{~h}$ after different durations of annealing [65-67], shown in Fig. 3a-f, shows diameters of about $2 \mu \mathrm{m}$. The prepared electrospun PCL/PEO nanofibers with a diameter of approximately $2 \mu \mathrm{m}$ shows a smooth surface in Fig. 3a. Compared to the fibers treated with SVA, a slight wrinkle-like structure appeared after one day of annealing (Fig. 3b). By comparison, PCL/PEO fibers undergoing 2 days (Fig. 3c) of SVA treatment generated secondary hierarchical nanostructures that were more pronounced and denser, and the PCL/PEO fibers undergoing 3 days of SVA treatment exhibited a deep and an uneven layered structure (Fig. 3d). Compared with Fig. 3d, Fig. 3e illustrates a deeper and uniform layered structure. With 5 days of SVA treatment, clear lamella-like petal structures appear on the fiber surface, uniform and dense, indicating that longer aging time results in more perfect crystal growth (Fig. 3f).

In addition, the PCL/PEO fibers (Sample 1) prepared for different SVA treatment durations were characterized by XRD, which was important for self-assembled composite materials [68-75]. The XRD pattern of PCL (Fig. 4a) shows characteristic diffraction peaks at $21.4^{\circ}$ and $23.7^{\circ}$. The PEO diffraction pattern exhibits two intense characteristic peaks located at $19.3^{\circ}$ and $23.6^{\circ}$, whereas PCL/PEO components show three main peaks at $19.3^{\circ}, 21.4^{\circ}$, and $23.6^{\circ}$, which indicate that the PCL/PEO components contain both PCL and PEO. Fig. $4 \mathrm{~b}$ shows the diffraction patterns of the prepared air filtration mat with different SVA treatment durations. The characteristic peak located at $21.4^{\circ}$ shows a sharper tendency with the increment of SVA time, which indicates a change in the crystallinity of PCL/PEO composites. This is a better proof of the structural phenomenon in Fig. 3. In addition, 
a

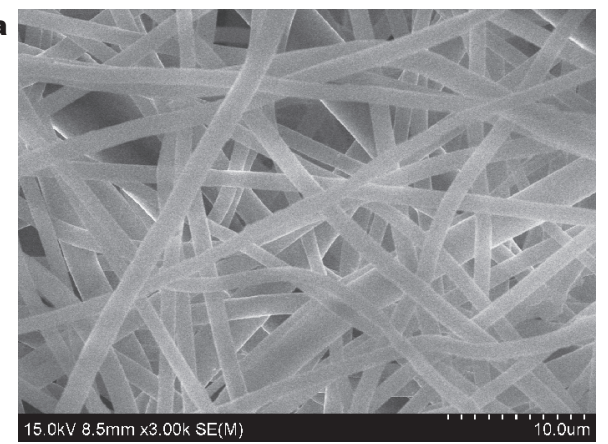

b

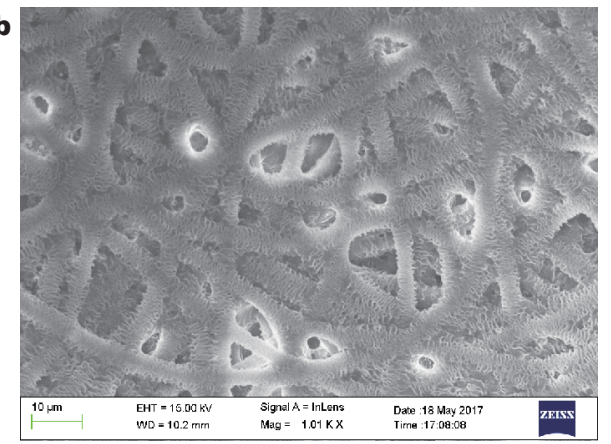

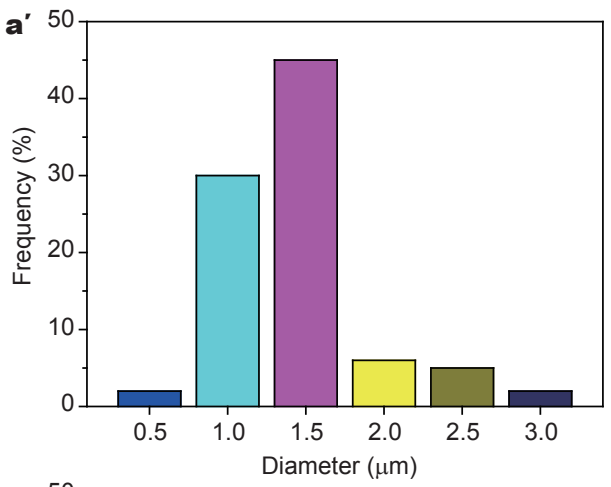

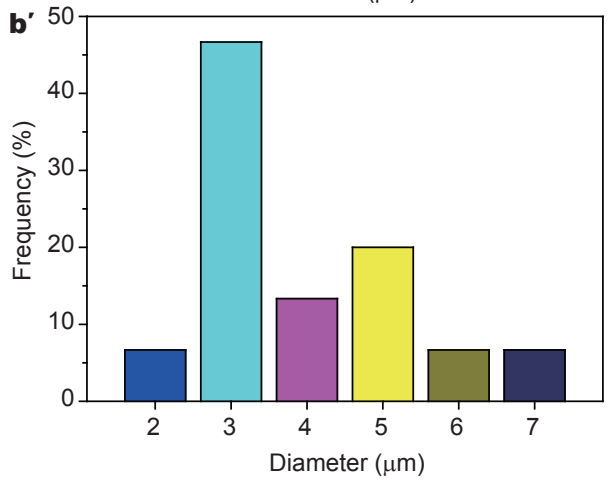

Figure 2 (a) SEM images and fiber diameter size distributions of the prepared PCL/PEO nanofibers mat (Sample 1) by electrospinning (a and a') and subsequent by SVA treatment for 5 day (b and $\left.b^{\prime}\right)$.
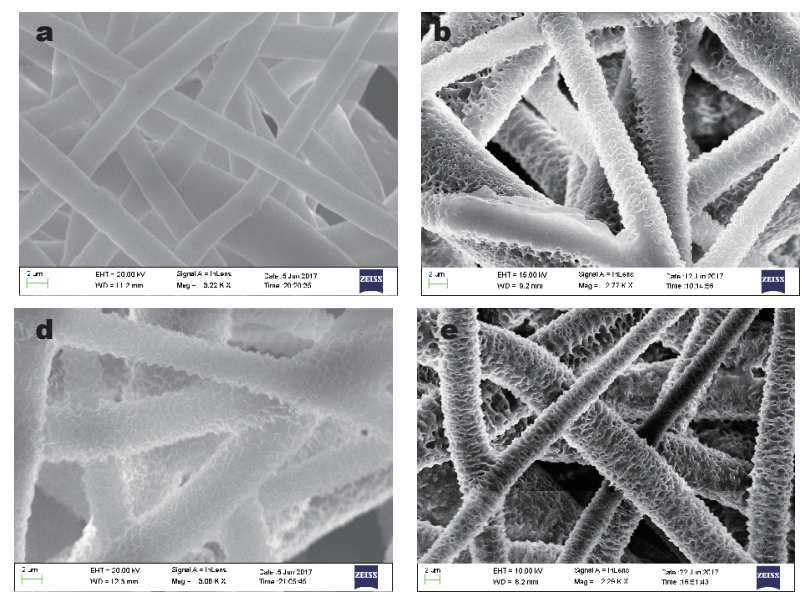
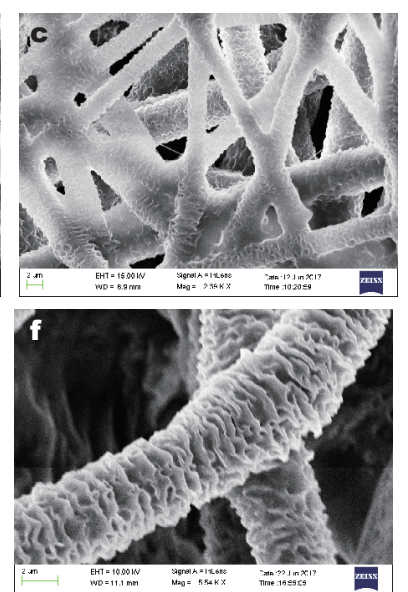

Figure 3 SEM images of the prepared electrospun PCL/PEO nanofibers (a, Sample 1) and SVA treatment at different time intervals: (b), one day; (c), 2 days; (d), 3 days; (e), 4 days; (f), 5 days.

Fig. 5 demonstrates the thermograms of PCL/PEO primary fibers and PCL/PEO fibers with 5 days of SVA treatment (Sample $\left.1_{\mathrm{SVA}}\right)$. More specifically, both samples began to decompose from $280^{\circ} \mathrm{C}$ and stabilized after $450^{\circ}$ $\mathrm{C}$, which may be the result of various oxygenated chemical groups and alkyl chain pyrolysis in hightemperature environments. The quality retention rates demonstrate the values of $8.97 \%$ and $4.27 \%$ for PCL/PEO nanofiber mats before and after SVA treatment. According to the above TG results, the SVA-treated PCL/PEO fibers show a slight decrease in the thermal stability compared to PCL/PEO fibers because of the surface lamella-like petal structures that originate from more uniform crystallinity and nanostructures of high regular- 

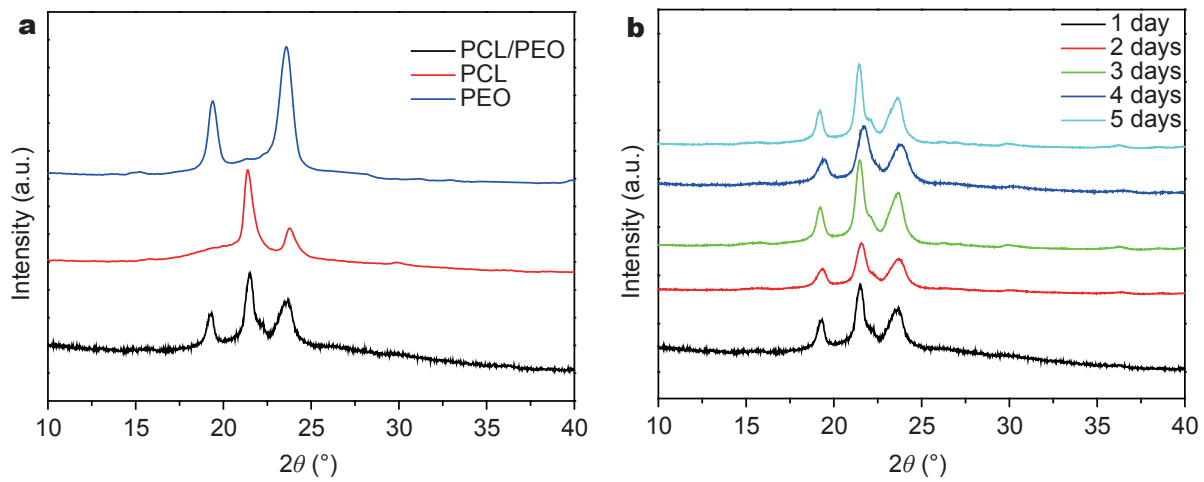

Figure 4 XRD patterns of the prepared PCL/PEO nanofibers (a) and with different subsequent SVA treatment time intervals (b).

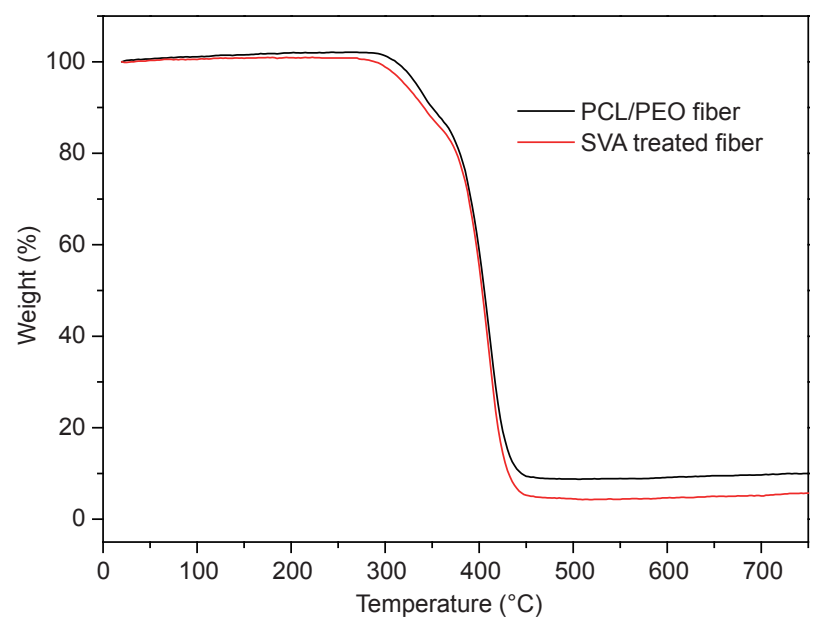

Figure 5 TG curves and infrared spectra of the PCL/PEO nanofiber mat by electrospinning and subsequent SVA treatment time of 5 days.

ity after SVA treatment $[45,46]$. It is important to note that PCL crystallite growth is apparently restricted by the PEO phase with a rigid and more densely packed semicrystalline structure. In this case, the spherulitic growth of PCL is suppressed because of the spatial confinement of the semicrystalline PEO phase. Meanwhile, thicker fibers favor the spherulitic growth of PCL, resulting in a PCL phase that can crystallize simultaneously throughout the surfaces of electrospun fibers [57].

\section{PM2.5 removal performances of air filtration mats}

The filtration properties of the fabricated PCL/PEO mats were examined in the PM2.5 filtration experiments. In this experiment, PM2.5 is generated by burning moxa stick incense. The burning moxa stick contains PM2.5 smoke with $\mathrm{CO}, \mathrm{CO}_{2}$, and many volatile organic compounds that are similar to PM2.5 in real haze that forms over big cities. The filtration experiments were performed on the PCL/PEO air filtration mats, and the results, test equipment, and the test methods are presented in Fig. 6. In this study, the air filtration mat performance was evaluated using a PM2.5 mask filtration efficiency measuring device that consists of four parts: an air inlet, a measuring cavity, a fan, and an air outlet (Fig. 6a). When the fan switch is turned on, the air flow containing PM2.5 enters the measuring cavity at a flow rate of $600 \mathrm{~L} \mathrm{~min}^{-1}$. At the beginning of the experiment, the real-time PM2.5 particle concentrations could be recorded by the sensors in the measuring cavity showing a stable number. Then, the test sample was sealed with a rubber band on the top of the measuring cavity immediately (Fig. 6c), and the particle density was measured and recorded every $5 \mathrm{~s}$ over a total test time of $3 \mathrm{~min}$. To ensure the accuracy of the experimental results, each experiment was repeated 5 times and averaged. The removal of PM2.5 was related to the volume of the spinning precursor solution. To determine the volume, Sample 1 was selected with different precursor solution volumes to test the filter performance. Fig. $6 \mathrm{~d}$ shows the filtration curves of the PCL/PEO air filtration mat with precursor solution volumes of 2, 2.5, 3, 3.5 , and $4 \mathrm{~mL}$, respectively. In order to evaluate the air filtration mat before SVA treatment, the PM2.5 removal rates were obtained for several different volumes: $57.31 \%$ removal at $2 \mathrm{~mL}, 65 \%$ removal at $2.5 \mathrm{~mL}, 68.5 \%$ removal at $3 \mathrm{~mL}, 67.43 \%$ removal at $3.5 \mathrm{~mL}$, and $67.31 \%$ removal at $4 \mathrm{~mL}$. After SVA treatment, the values were $68.89 \%$ at $2 \mathrm{~mL}, 69.01 \%$ at $2.5 \mathrm{~mL}, 71.37 \%$ at $3 \mathrm{~mL}, 70.72 \%$ at 3.5 $\mathrm{mL}$, and $69.53 \%$ at $4 \mathrm{~mL}$ (Fig. $6 \mathrm{~d}$ ). The optimum volume was found to be $3 \mathrm{~mL}$, which had sufficient air penetration and resulted in the best PM2.5 removal rate. Therefore, the volume of $3 \mathrm{~mL}$ was chosen for follow-up experiments. The PM2.5 removal efficiencies of the air filtration mat with different volumes and the comparison 

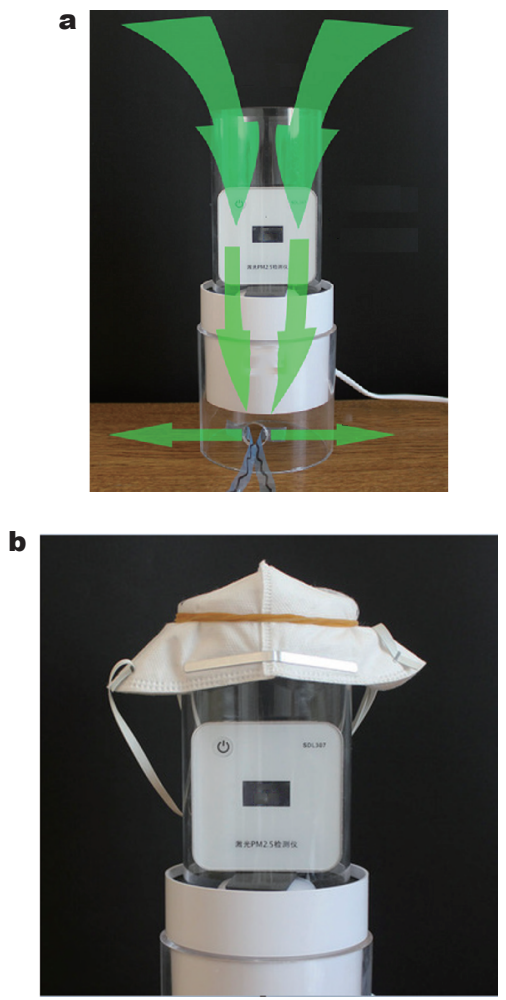
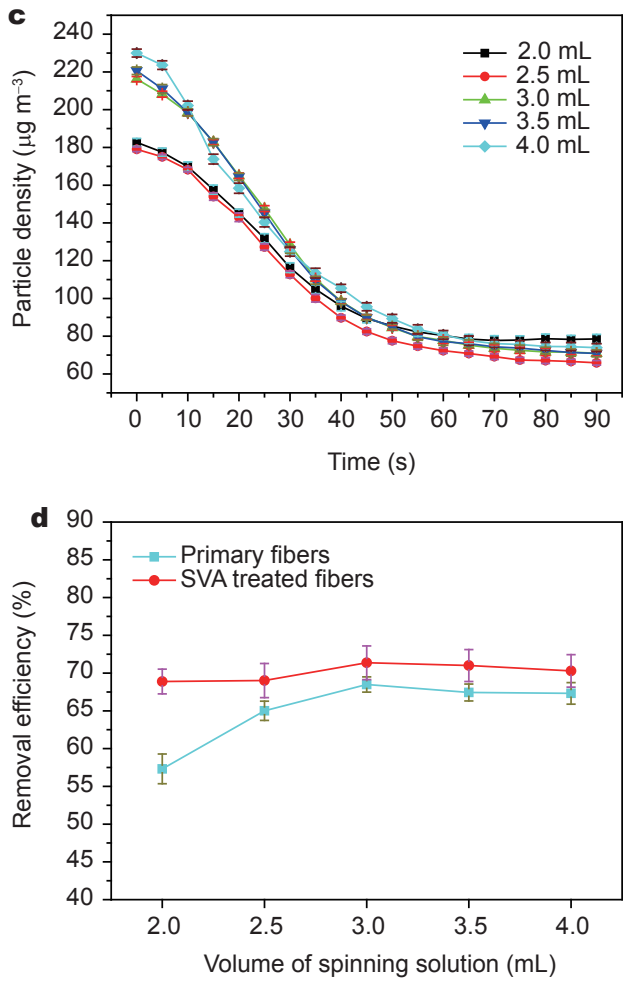

Figure 6 Schematics of the air filtration mat that captured PM2.5 by air flow (a) and working state with mask filtration (b); (c) PM2.5 filtration curves for the air filtration mat (Sample 1) with different volumes of spinning precursor solution; (d) PM2.5 removal efficiency plots for primary fibers and SVA-treated fibers.

of PM2.5 removal efficiencies of the air filtration mat before and after SVA treatment are presented in Fig. 6d. Another important factor that affects the PM2.5 removal performance is the surface structure of the fiber. Compared to the primary fibers, the SVA-treated fibers with the same parameters of $15 \mathrm{kV}, 25 \mathrm{~cm}$, and $1 \mathrm{~mL} \mathrm{~h}^{-1}$ and the same volume of $3 \mathrm{~mL}$ show significantly increased PM2.5 removal efficiencies by about $6.37 \%$ with increasing the specific surface area.

Besides the volume of the spinning precursor solution and the surface structure of the fiber, another important parameter for the air filtration mat is the filter's dimension, which also affects the PM2.5 removal efficiency [76-78]. In this study, we used an air filtration mat with two other parameters (Sample 2 and Sample 3) to test the PM2.5 removal efficiency. The average fiber diameters of Sample 2 and Sample 3 are of $2.5 \pm 0.4$ and 4 $\pm 0.5 \mu \mathrm{m}$, respectively, as shown in Fig. $7 \mathrm{a}^{\prime}$ and $c^{\prime}$. As shown in Fig. 7b' and d', the average fiber diameters of Sample $2_{\text {SVA }}$ (Sample 2 with 5 days of SVA treatment) and Sample $3_{\text {SVA }}$ (Sample 3 with 5 days of SVA treatment) are, respectively, of $6 \pm 1.1$ and $4.5 \pm 1.2 \mu \mathrm{m}$, indicating that the fiber diameter slightly increased and became relatively uniform after SVA treatment.

The PM2.5 filtration column chart of different air filtration mats is shown in Fig. 8. PM2.5 removal efficiencies reach $77.92 \%$ and $77.97 \%$ for Sample 2 and Sample 3, respectively. In the controlled experiment of air filtration nanocomposite mats with different fiber diameters, the removal performances of PM2.5 were significantly different. Sample 3 with $15 \mathrm{kV}, 15 \mathrm{~cm}$, and $1 \mathrm{~mL} \mathrm{~h}^{-1}$ had the characteristics of uneven diameter, high porosity, and high packing density, so as to obtain a higher PM2.5 removal efficiency. For the SVA-treated fibers shown in Fig. 8a, Sample $2_{\text {SVA }}$ had a PM2.5 removal efficiency of $77.14 \%$ and Sample $3_{\text {SVA }}$ had a PM2.5 removal efficiency of $80.01 \%$. Therefore, the PM2.5 removal efficiency of Sample $3_{\mathrm{SVA}}$ was optimal, corresponding to the experimental results shown in Fig. 8a. Sample $3_{\text {SVA }}$ has the highest PM2.5 removal rate, since crude fibers serve as a kind of framework, playing a supporting role in the deposition of finer fibers in the fiber membrane, increasing the looseness between fibers, and improving the porosity of the fiber membrane [47]. 

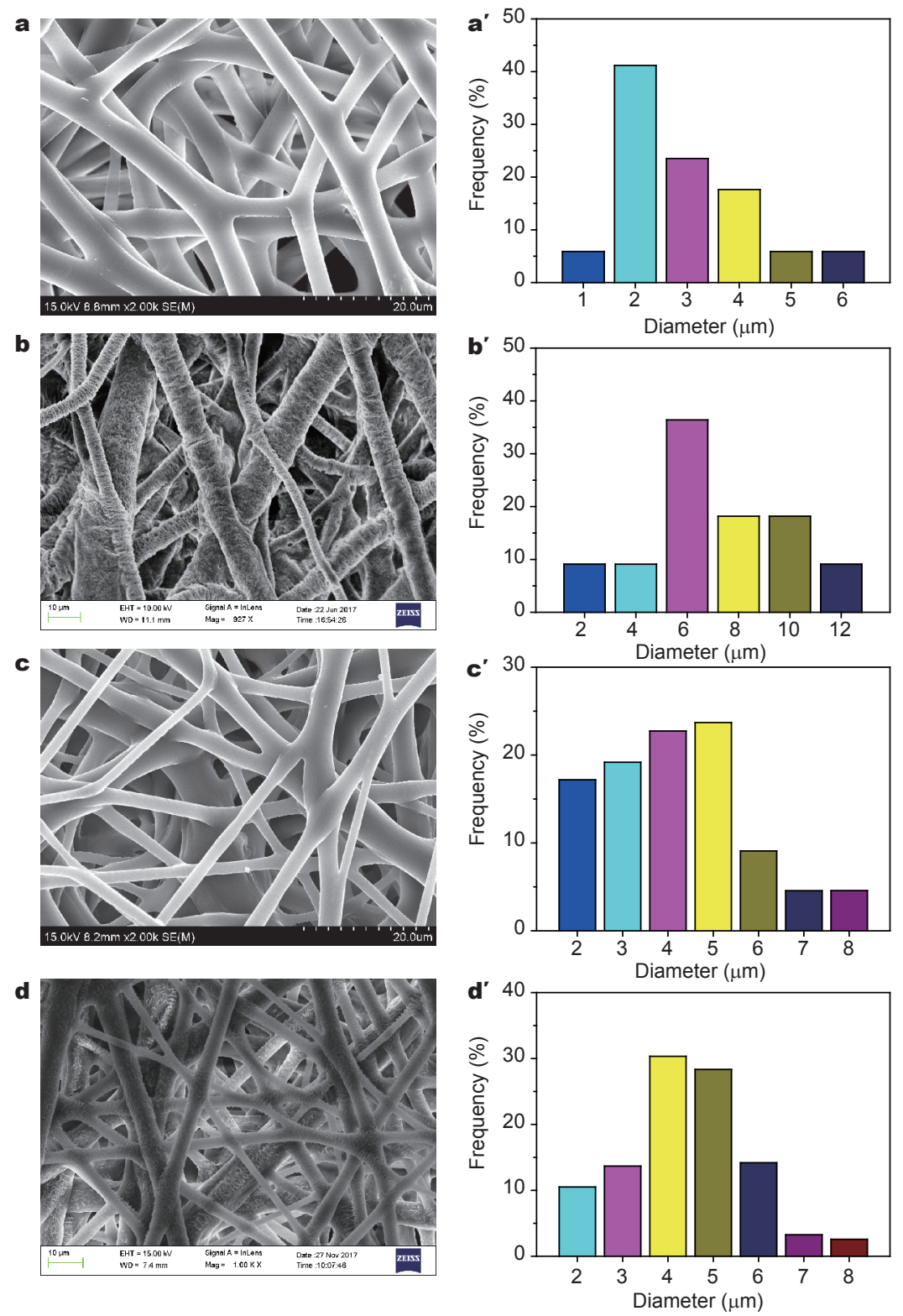

Figure 7 SEM images and fiber diameter size distributions of the prepared PCL/PEO nanofiber mat by electrospinning (Sample 2, a and a'; Sample 3, $\mathrm{c}$ and $\mathrm{c}^{\prime}$ ) and subsequently with SVA treatment at a time of 5 days (Sample 2, b and b'; Sample 3, d and d').

In addition, in order to study the efficiency of our air filtration mat (Sample $3_{\mathrm{SvA}}$ ) on a truly contaminated hazy day, we conducted a field test on 29 December 2017 in Qinhuangdao, China. The concentration of PM2.5 on that day was $250 \mu \mathrm{g} \mathrm{m}^{-3}$, which is considered serious air pollution. The Sample $3_{\mathrm{SVA}}$ air filtration mat achieved a PM2.5 removal efficiency of $73.75 \%$. An error bar represents the standard deviation of four replicate measurements. In this experiment, by adjusting the spinning parameters of the air filtration mat, the PM2.5 removal efficiency was increased by about 9\%. For Sample 2 and Sample 3, with SVA treatment, the PM2.5 removal efficiencies increased by $2.63 \%$ and $2.09 \%$, respectively. As a result, we designed and successfully prepared a high-efficiency air filtration mat using three steps: quantitative precursor spinning solution with $3 \mathrm{~mL}$, suitable electrostatic spinning parameters with $15 \mathrm{kV}, 15$ $\mathrm{cm}$, and $1 \mathrm{~mL} \mathrm{~h}^{-1}$, and SVA treatment under appropriate conditions.

To further compare the PM2.5 filter performance of the 

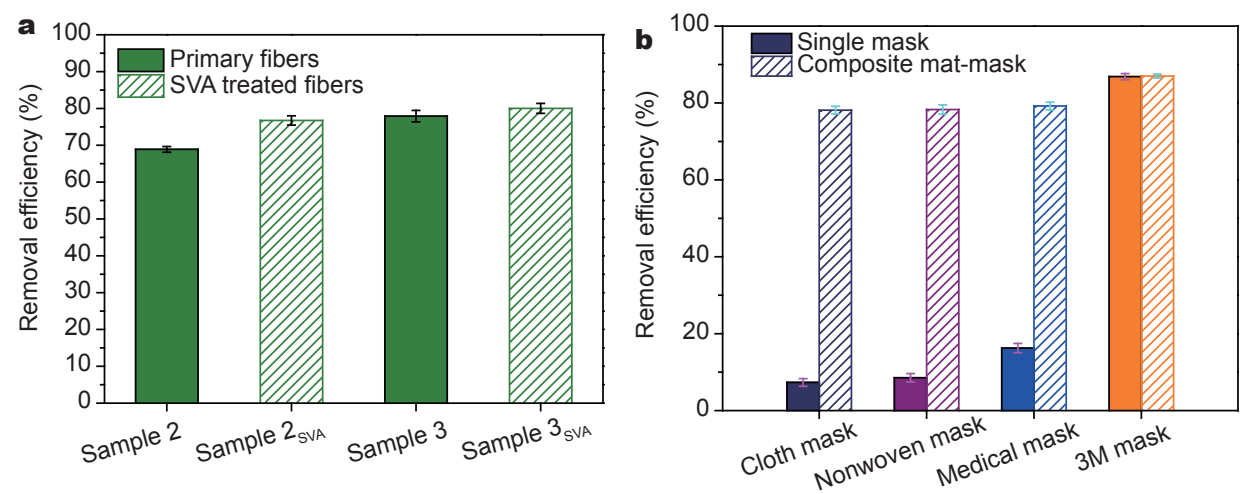

Figure 8 (a) Comparison chart of PM2.5 removal efficiency of Sample 2 and Sample 3 with/without SVA treated fibers. (b) Comparison chart of PM2.5 removal efficiency of Sample 3 deposited on different commercial masks.

air filter mat, we chose and investigated commercial masks with different texture materials, as seen in Fig. 8b. The results indicated that the PM2.5 filter performance of the cloth mask was $7.32 \%$, with values of $8.53 \%, 16.26 \%$, and $86.85 \%$ for the nonwoven mask, medical mask, and the $3 \mathrm{M}$ mask, respectively. It could be easily observed that most of the masks, except for the $3 \mathrm{M}$ mask, have relatively low PM2.5 removal efficiencies and fail to trap PM2.5 and protect human life [79]. To meet this challenge, we deposited the prepared air filter mat onto the surface of commercial masks and then tested the filter performance. It should be noted that, after compositing with the air filtration mat, the PM2.5 removal efficiency of commercial masks increased significantly $78.14 \%$ for cloth masks, $78.31 \%$ for nonwoven masks, $79.22 \%$ for medical masks, and $87 \%$ for $3 \mathrm{M}$ masks). In addition, it should be further noted that the SVA-treated PCL/PEO air filter mat showed clear advantages, such as a simple and ecofriendly preparation process, easy degradation nature, controllable nanostructures, low material cost, and wide combinations with different mask substrates, demonstrating potential applications with high filtration efficiency and wide fields compared with the commercial $3 \mathrm{M}$ masks. Hence, air filtration mat-anchored masks have shown improved filtration performance. Furthermore, composite materials that were reported in previous work are shown in Table 1, which clearly demonstrated various characteristics of different air filtration mats in the filtration process $[24,27,28,36,37,80-82]$. For example, Wang et al. [28] prepared porous bead-on-string PLA nanofibers by electrospinning, and the obtained nanofibrous membranes exhibited an excellent filtration efficiency with a low pressure drop. Our present study shows significant advantages in the PM2.5 removal efficiency, good reusability, and stability. It is expected that, due to the SVA treatment, the 3D nanowrinkled structure can provide new idea for respiratory protection, air purification, and 3D nanomaterial design.

To further study the ability of air filtration mats to capture PM2.5, we investigated the composition and surface chemistry of PM2.5. The air filtration mat and mask with fibers were sealed in the instrument, which was exposed to outdoor haze air (PM2.5 mass concentration larger than $225 \mathrm{mg} \mathrm{m}^{-3}$ ), and the fan was turned on to let the air containing PM2.5 pass through for $24 \mathrm{~h}$, trapping PM2.5. Masks with respective capture of PM2.5 are shown in Fig. 9a. The surface of the mask with fibers becomes dirty after capturing PM2.5. In order to further study PM2.5, we studied the capture of PM2.5 by fibers. From the SEM image, we can see that PM2.5 particles are irregular in shape and easily adhere to and agglomerate on the fiber surface (Fig. 9b). TEM images of PM2.5 captured by fibers are shown in Fig. 9c. PM2.5 aggregates have sizes of around $700 \mathrm{~nm}$. Energy-dispersive spectrometry (EDS) shows that the PM2.5 particles contain more complex components, mainly $\mathrm{C}$ and $\mathrm{O}$ elements and a little $\mathrm{Ca}, \mathrm{Fe}$, and other metals (Fig. 9b).

To further study the composition of PM2.5, an XPS analysis was performed on Sample 1 before (Fig. 10a and b) and after (Fig. 10c and d) the filtration of haze. We exposed Sample 1 to outdoor hazy air for $48 \mathrm{~h}$ and then carried out an XPS test of PM2.5. Fig. 10a conveys that the C $1 \mathrm{~s}$ signal mainly is located at $284.8,285.5,286.5$, and $288.7 \mathrm{eV}$, corresponding to $\mathrm{C}-\mathrm{OH}, \mathrm{C}-\mathrm{O}, \mathrm{C}=\mathrm{O}$, and $\mathrm{O}=\mathrm{C}-\mathrm{O}$ bonds, respectively. The XPS spectra with $\mathrm{O} 1 \mathrm{~s}$ survey data from Sample 1 before filtration of haze are shown in Fig. 10b, which clarifies the position of five peaks at $531.7,532.7$, and $533.5 \mathrm{eV}$ that represent the bonds of $\mathrm{C}=\mathrm{O}, \mathrm{C}-\mathrm{O}$, and $-\mathrm{O}-\mathrm{H}$, respectively. In addition, Sample 1, after the filtration of haze, shows that the $\mathrm{C} 1 \mathrm{~s}$ 
Table 1 Comparative characteristics and filtration performance of different materials reported in the literatures

\begin{tabular}{|c|c|c|c|c|c|c|}
\hline No. & Materials & $\begin{array}{l}\text { Fiber diameter } \\
\qquad(\mathrm{nm})\end{array}$ & Filter media & Advantages & Disadvantage & Ref. \\
\hline 1 & $\begin{array}{l}\text { Polyacrylonitrile } \\
\text { (PAN) }\end{array}$ & 200 & Incense smoke & $\begin{array}{c}\text { Transparent, environ- } \\
\text { mentally high stability } \\
\text { and highly effective re- } \\
\text { moval of PM } 2.5\end{array}$ & $\begin{array}{l}\text { Low reusability, easy to } \\
\text { aging, low strength, poor } \\
\text { wear resistance }\end{array}$ & {$[27]$} \\
\hline 2 & $\begin{array}{l}\text { Polylactic acid } \\
\text { (PLA) }\end{array}$ & $150-300$ & $\begin{array}{c}\mathrm{NaCl} \\
\text { aerosol }\end{array}$ & $\begin{array}{c}\text { Controllable morphology, } \\
\text { excellent filtration effi- } \\
\text { ciency and a low pressure } \\
\text { drop }\end{array}$ & $\begin{array}{l}\text { Poor stability, poor wear } \\
\text { resistance and easy to } \\
\text { aging }\end{array}$ & {$[28]$} \\
\hline 3 & Nylon6 (PA-6) & 150 & $\begin{array}{c}\mathrm{NaCl} \\
\text { aerosol }\end{array}$ & $\begin{array}{l}\text { Good stability, good air } \\
\text { permeability and good } \\
\text { PM2.5 remove }\end{array}$ & $\begin{array}{l}\text { Easy to aging and low } \\
\text { intensity }\end{array}$ & {$[80]$} \\
\hline 4 & $\begin{array}{l}\text { Polyurethanes } \\
\qquad(\mathrm{PU})\end{array}$ & 120 & $\begin{array}{l}\text { Ammnium } \\
\text { sulphate }\end{array}$ & $\begin{array}{l}\text { Excellent elasticity, good } \\
\text { abrasion resistance and } \\
\text { good PM2.5 remove }\end{array}$ & $\begin{array}{l}\text { Poor stability and easy to } \\
\text { aging }\end{array}$ & {$[24]$} \\
\hline 5 & $\begin{array}{c}\text { Nylon6/polyacrylonitrile } \\
\text { (N6/PAN) }\end{array}$ & 272 & $\mathrm{NaCl}$ aerosol & $\begin{array}{l}\text { High porosity, high fil- } \\
\text { tration efficiency and } \\
\text { good stability. }\end{array}$ & $\begin{array}{l}\text { Poor air permeability, } \\
\text { poor cycle performance }\end{array}$ & {$[81]$} \\
\hline 6 & $\begin{array}{l}\text { Polyvinyl chloride /poly- } \\
\text { urethane } \\
\text { (PVC/PU) }\end{array}$ & 960 & $\begin{array}{c}\mathrm{NaCl} \\
\text { aerosol }\end{array}$ & $\begin{array}{l}\text { Good tensile strength, } \\
\text { high abrasion resistance } \\
\text { and high filtration effi- } \\
\text { ciency }\end{array}$ & $\begin{array}{l}\text { Poor cycle performance } \\
\text { and easy to aging }\end{array}$ & {$[37]$} \\
\hline 7 & $\begin{array}{l}\text { Polyacrylonitrile /polyur- } \\
\text { ethane (PAN/PU) }\end{array}$ & 175 & $\begin{array}{c}\mathrm{NaCl} \\
\text { aerosol }\end{array}$ & $\begin{array}{l}\text { Superhydrophobicity, } \\
\text { controllable morphology, } \\
\text { porous structure }\end{array}$ & $\begin{array}{l}\text { Poor air permeability, } \\
\text { poor cycle performance }\end{array}$ & {$[36]$} \\
\hline 8 & $\begin{array}{c}\text { Polyacrylonitrile /silica } \\
\text { nanoparticles }\left(\mathrm{PAN} / \mathrm{SiO}_{2} \text { ) }\right.\end{array}$ & $600-700$ & $\begin{array}{c}\mathrm{NaCl} \\
\text { aerosol }\end{array}$ & $\begin{array}{l}\text { Layer-by-layer assisted } \\
\text { stacking structure and } \\
\text { high filtration efficiency }\end{array}$ & $\begin{array}{l}\text { Stability is poor, low } \\
\text { strength, poor wear re- } \\
\text { sistance }\end{array}$ & {$[82]$} \\
\hline 9 & Present work & $2,000-5,000$ & smoke & $\begin{array}{l}\text { Adjustable nanostructure, } \\
\text { high strength, high stabi- } \\
\text { lity and high toughness }\end{array}$ & $\begin{array}{l}\text { Sensitive to temperature } \\
\text { and solvents }\end{array}$ & \\
\hline
\end{tabular}
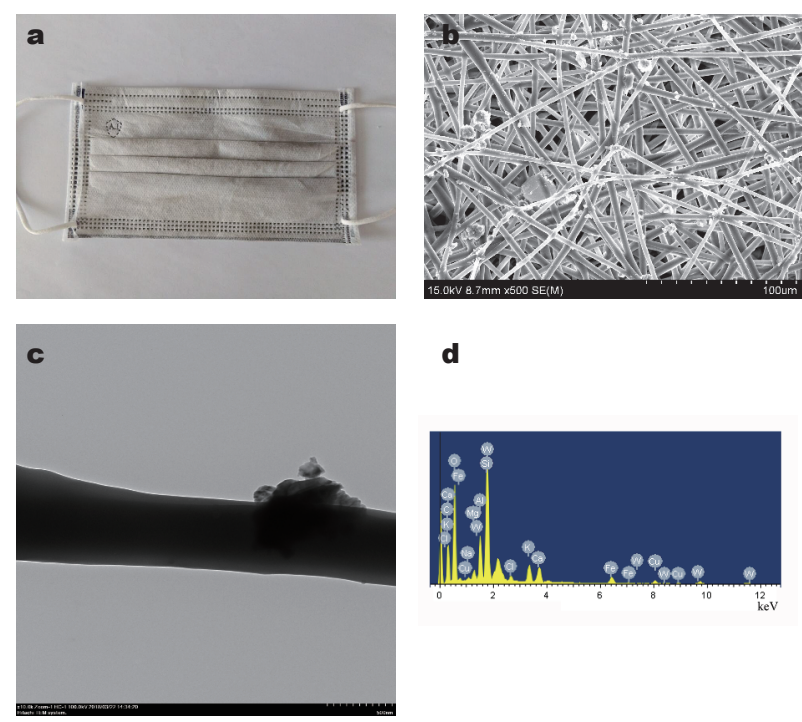

Figure 9 (a) Photo of a commercial mask covered with an electrospun mat (Sample 1) after air filtration; (b, c) TEM and SEM characterization of the morphologies of Sample 1 attached to PM2.5 particles; (d) EDX composition analysis of PM2.5 particles. signal mainly consists of three peaks at 284.6, 285.3, and $288.7 \mathrm{eV}$, which represent the bonds of $\mathrm{C}-\mathrm{OH}, \mathrm{C}-\mathrm{O}$, and $\mathrm{O}=\mathrm{C}-\mathrm{O}$, respectively (Fig. 10c). Moreover, the $\mathrm{O} 1 \mathrm{~s}$ peaks are located at 531.7, 532.5, and $533.5 \mathrm{eV}$, corresponding to $\mathrm{C}=\mathrm{O}, \mathrm{C}-\mathrm{O}$, and $-\mathrm{O}-\mathrm{H}$ bonds, respectively (Fig. 10d). The overall results show that $\mathrm{C}$ and $\mathrm{O}$ are the primary elements on the PM2.5 surface with functional groups of $\mathrm{C}-\mathrm{C}, \mathrm{C}-\mathrm{O}$, and $\mathrm{C}=\mathrm{O}$ [27]. The results of the XPS analysis of PM2.5 correspond to the results of elemental analysis of the energy spectrum (Fig. 9).

\section{CONCLUSIONS}

In summary, we have demonstrated that electrospun PCL/PEO air filtration mats can act as highly effective PM2.5 filters because of their lamella-like petals, thickness of uneven fiber diameter, packing density, and surface chemistry. These air filtration mats can effectively prevent PM2.5 from entering the human respiratory tract; thereby they protect humans who carry out activities outdoors on hazy days. An electrospun PCL/PEO air 

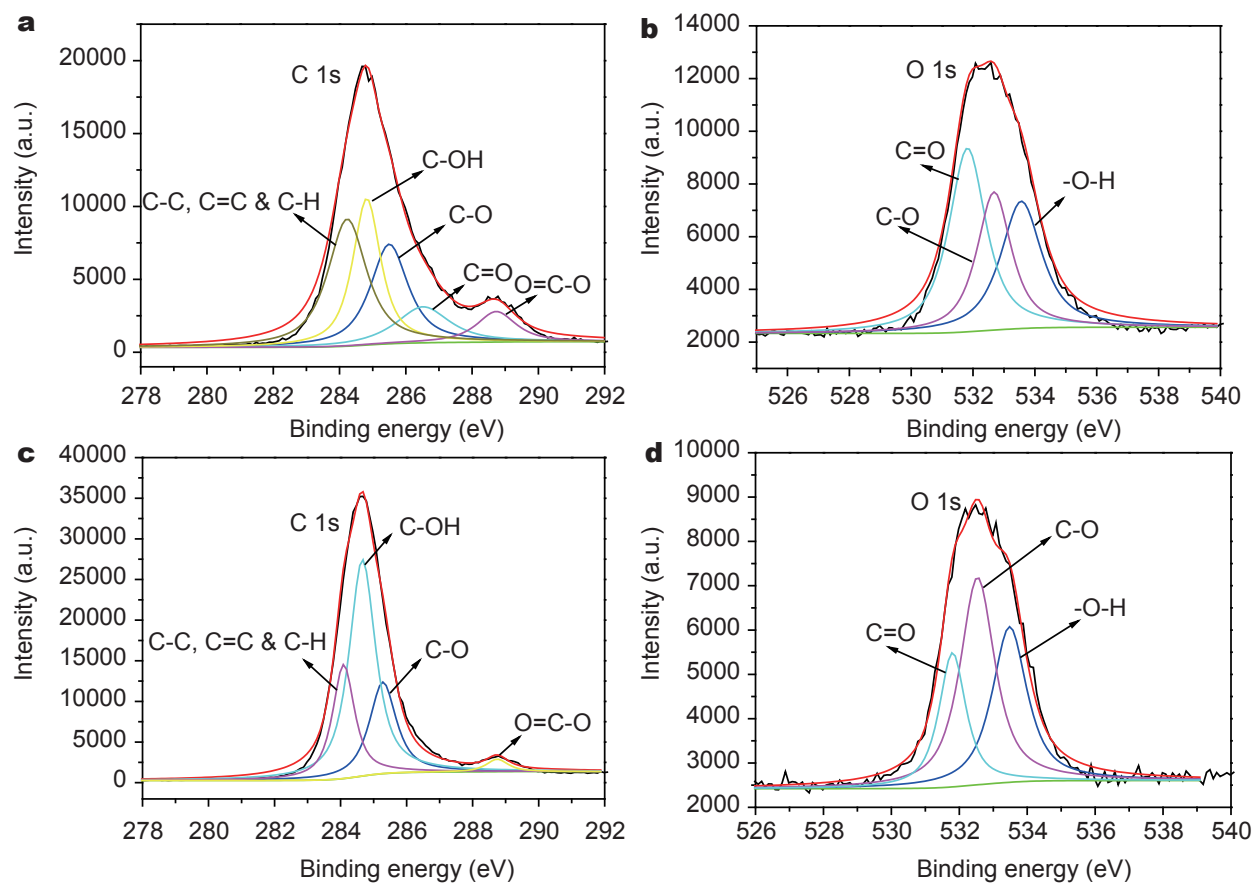

Figure $10 \mathrm{C}$ 1s and O 1s deconvolutions in the XPS profiles of electrospun mat (Sample 1) before (a, b) and after (c, d) air filtration.

filtration mat with a volume of $3 \mathrm{~mL}$ spinning precursor fluid and 5 days of SVA treatment can be used under simulated environmental conditions, with a PM2.5 removal efficiency maintained at $80.01 \%$. This air filtration mat was also evaluated by a field test in Qinhuangdao with a PM2.5 removal efficiency of 73.75\%. We found that our air filtration mat integrated with commercial masks can be used as a new filter mask to provide protection in outdoor environments. In addition, this air filtration mat can be regenerated and demonstrate excellent reusability. The present study is expected to open new avenues for the design and preparation of ecofriendly air filtration mats that can be easily integrated into commercial masks, which could filter PM2.5 out of the air more efficiently if the SVA treatment method is used.

Received 28 May 2018; accepted 2 July 2018; published online 8 August 2018

1 Zhang R, Jing J, Tao J, et al. Chemical characterization and source apportionment of PM2.5 in Beijing: seasonal perspective. Atmos Chem Phys, 2013, 13: 7053-7074

2 Li K, Jiao T, Xing R, et al. Fabrication of tunable hierarchical MXene@AuNPs nanocomposites constructed by self-reduction reactions with enhanced catalytic performances. Sci China Mater, 2018, 61: 728-736

3 Cheng C. Interfacial behaviors of PMMA-PEO block copolymers at the air/water interface. Sci China Ser B, 2005, 48: 567-573

4 Zhao H, Jiao T, Zhang L, et al. Preparation and adsorption capacity evaluation of graphene oxide-chitosan composite hydrogels. Sci China Mater, 2015, 58: 811-818

5 Sun Z, Liao T, Kou L. Strategies for designing metal oxide nanostructures. Sci China Mater, 2017, 60: 1-24

6 Liang Q, Li Z, Bai Y, et al. Reduced-sized monolayer carbon nitride nanosheets for highly improved photoresponse for cell imaging and photocatalysis. Sci China Mater, 2017, 60: 109-118

7 Wang D, Wang R, Liu L, et al. Down-shifting luminescence of water soluble $\mathrm{NaYF}_{4}: \mathrm{Eu}^{3+} @ \mathrm{Ag}$ core-shell nanocrystals for fluorescence turn-on detection of glucose. Sci China Mater, 2017, 60: 6874

8 Streets DG, Wu Y, Chin M. Two-decadal aerosol trends as a likely explanation of the global dimming/brightening transition. Geophys Res Lett, 2006, 33: 292-306

9 Harrison RM, Yin J. Particulate matter in the atmosphere: which particle properties are important for its effects on health? Sci Total Environ, 2000, 249: 85-101

10 Chow JC, Watson JG, Mauderly JL, et al. Health effects of fine particulate air pollution: lines that connect. J Air Waste Manage Association, 2006, 56: 1368-1380

11 Betha R, Behera SN, Balasubramanian R. 2013 Southeast Asian smoke haze: Fractionation of particulate-bound elements and associated health risk. Environ Sci Technol, 2014, 48: 4327-4335

12 Wu S, Deng F, Wei H, et al. Association of cardiopulmonary health effects with source-appointed ambient fine particulate in Beijing, China: A combined analysis from the healthy volunteer natural relocation (HVNR) study. Environ Sci Technol, 2014, 48: 34383448

13 Brook RD, Rajagopalan S, Pope CA, et al. Particulate matter air 
pollution and cardiovascular disease: an update to the scientific statement from the American Heart Association. Circulation, 2010, 121: 2331-2378

14 Anenberg SC, Horowitz LW, Tong DQ, et al. An estimate of the global burden of anthropogenic ozone and fine particulate matter on premature human mortality using atmospheric modeling. Environ Health Perspect, 2010, 118: 1189-1195

15 Timonen KL, Vanninen E, de Hartog J, et al. Effects of ultrafine and fine particulate and gaseous air pollution on cardiac autonomic control in subjects with coronary artery disease: The ULTRA study. J Expo Sci Environ Epidemiol, 2006, 16: 332-341

16 Reneker DH, Chun I. Nanometre diameter fibres of polymer, produced by electrospinning. Nanotechnology, 1996, 7: 216-223

17 Si Y, Wang X, Li Y, et al. Optimized colorimetric sensor strip for mercury(II) assay using hierarchical nanostructured conjugated polymers. J Mater Chem A, 2014, 2: 645-652

18 Li D, Xia Y. Electrospinning of nanofibers: reinventing the wheel? Adv Mater, 2004, 16: 1151-1170

19 Lin J, Ding B, Yang J, et al. Subtle regulation of the micro- and nanostructures of electrospun polystyrene fibers and their application in oil absorption. Nanoscale, 2012, 4: 176-182

20 Matulevicius J, Kliucininkas L, Prasauskas T, et al. The comparative study of aerosol filtration by electrospun polyamide, polyvinyl acetate, polyacrylonitrile and cellulose acetate nanofiber media. J Aerosol Sci, 2016, 92: 27-37

21 Li J, Gao F, Liu LQ, et al. Needleless electro-spun nanofibers used for filtration of small particles. Express Polym Lett, 2013, 7: 683689

22 Kim HJ, Pant HR, Choi NJ, et al. Composite electrospun fly ash/ polyurethane fibers for absorption of volatile organic compounds from air. Chem Eng J, 2013, 230: 244-250

23 Scholten E, Bromberg L, Rutledge GC, et al. Electrospun polyurethane fibers for absorption of volatile organic compounds from air. ACS Appl Mater Interfaces, 2011, 3: 3902-3909

24 Sambaer W, Zatloukal M, Kimmer D. 3D air filtration modeling for nanofiber based filters in the ultrafine particle size range. Chem Eng Sci, 2012, 82: 299-311

25 Barhate RS, Loong CK, Ramakrishna S. Preparation and characterization of nanofibrous filtering media. J Membrane Sci, 2006, 283: 209-218

26 Gibson P, Schreuder-Gibson H, Rivin D. Transport properties of porous membranes based on electrospun nanofibers. Colloids Surfs A-Physicochem Eng Aspects, 2001, 187-188: 469-481

27 Liu C, Hsu PC, Lee HW, et al. Transparent air filter for highefficiency PM2.5 capture. Nat Commun, 2015, 6: 6205

28 Wang Z, Zhao C, Pan Z. Porous bead-on-string poly(lactic acid) fibrous membranes for air filtration. J Colloid Interface Sci, 2015, 441: 121-129

29 Huang ZM, Zhang YZ, Kotaki M, et al. A review on polymer nanofibers by electrospinning and their applications in nanocomposites. Composites Sci Tech, 2003, 63: 2223-2253

30 Ramakrishna S, Fujihara K, Teo WE, et al. Electrospun nanofibers: solving global issues. Mater Today, 2006, 9: 40-50

31 Bhardwaj N, Kundu SC. Electrospinning: A fascinating fiber fabrication technique. Biotech Adv, 2010, 28: 325-347

32 Kaur S, Sundarrajan S, Rana D, et al. Review: the characterization of electrospun nanofibrous liquid filtration membranes. J Mater Sci, 2014, 49: 6143-6159

33 Uyar T, Havelund R, Nur Y, et al. Molecular filters based on cyclodextrin functionalized electrospun fibers. J Membrane Sci, 2009,
332: $129-137$

34 Desai K, Kit K, Li J, et al. Nanofibrous chitosan non-wovens for filtration applications. Polymer, 2009, 50: 3661-3669

35 Kadam VV, Wang L, Padhye R. Electrospun nanofibre materials to filter air pollutants-A review. J Industrial Textiles, 2018, 47: 22532280

36 Wang N, Zhu Z, Sheng J, et al. Superamphiphobic nanofibrous membranes for effective filtration of fine particles. J Colloid Interface Sci, 2014, 428: 41-48

37 Wang N, Raza A, Si Y, et al. Tortuously structured polyvinyl chloride/polyurethane fibrous membranes for high-efficiency fine particulate filtration. J Colloid Interface Sci, 2013, 398: 240-246

38 Kayaci F, Uyar T. Electrospun polyester/cyclodextrin nanofibers for entrapment of volatile organic compounds. Polym Eng Sci, 2014, 54: 2970-2978

39 Vanangamudi A, Hamzah S, Singh G. Synthesis of hybrid hydrophobic composite air filtration membranes for antibacterial activity and chemical detoxification with high particulate filtration efficiency (PFE). Chem Eng J, 2015, 260: 801-808

40 Casper CL, Stephens JS, Tassi NG, et al. Controlling surface morphology of electrospun polystyrene fibers: effect of humidity and molecular weight in the electrospinning process. Macromolecules, 2004, 37: 573-578

41 Lee KH, Kim HY, Bang HJ, et al. The change of bead morphology formed on electrospun polystyrene fibers. Polymer, 2003, 44: 4029-4034

42 Xu X, Wang H, Jiang L, et al. Comparison between cellulose nanocrystal and cellulose nanofibril reinforced poly(ethylene oxide) nanofibers and their novel shish-kebab-like crystalline structures. Macromolecules, 2014, 47: 3409-3416

43 Wang B, Li B, Xiong J, et al. Hierarchically ordered polymer nanofibers via electrospinning and controlled polymer crystallization. Macromolecules, 2008, 41: 9516-9521

44 Chen X, Wang W, Cheng S, et al. Mimicking bone nanostructure by combining block copolymer self-assembly and $1 \mathrm{D}$ crystal nucleation. ACS Nano, 2013, 7: 8251-8257

45 Liu J, Bauer AJP, Li B. Solvent vapor annealing: an efficient approach for inscribing secondary nanostructures onto electrospun fibers. Macromol Rapid Commun, 2014, 35: 1503-1508

46 Wang L, Pai CL, Boyce MC, et al. Wrinkled surface topographies of electrospun polymer fibers. Appl Phys Lett, 2009, 94: 151916

47 Bonino CA, Efimenko K, Jeong SI, et al. Three-dimensional electrospun alginate nanofiber mats via tailored charge repulsions. Small, 2012, 8: 1928-1936

48 Lin J, Cai Y, Wang X, et al. Fabrication of biomimetic superhydrophobic surfaces inspired by lotus leaf and silver ragwort leaf. Nanoscale, 2011, 3: 1258-1262

49 Huang XF, Yun H, Gong ZH, et al. Source apportionment and secondary organic aerosol estimation of PM2.5 in an urban atmosphere in China. Sci China Earth Sci, 2014, 57: 1352-1362

50 Lim CT, Tan EPS, Ng SY. Effects of crystalline morphology on the tensile properties of electrospun polymer nanofibers. Appl Phys Lett, 2008, 92: 141908

51 Yian Chew S, Hufnagel TC, Teck Lim C, et al. Mechanical properties of single electrospun drug-encapsulated nanofibres. Nanotechnology, 2006, 17: 3880-3891

52 Wong SC, Baji A, Leng S. Effect of fiber diameter on tensile properties of electrospun poly(-caprolactone). Polymer, 2008, 49: 4713-4722

53 Pitt CG, Chasalow FI, Hibionada YM, et al. Aliphatic polyesters. I. 
The degradation of poly(e-caprolactone) in vivo. J Appl Polym Sci, 1981, 26: 3779-3787

54 Zhang Y, Mu Y, Meng F, et al. The pollution levels of BTEX and carbonyls under haze and non-haze days in Beijing, China. Sci Total Environ, 2014, 490: 391-396

55 Huang RJ, Zhang Y, Bozzetti C, et al. High secondary aerosol contribution to particulate pollution during haze events in China. Nature, 2014, 514: 218-222

56 Hou C, Jiao T, Xing R, et al. Preparation of $\mathrm{TiO}_{2}$ nanoparticles modified electrospun nanocomposite membranes toward efficient dye degradation for wastewater treatment. J Taiwan Institute Chem Engineers, 2017, 78: 118-126

57 Bauer AJP, Grim ZB, Li B. Hierarchical polymer blend fibers of high structural regularity prepared by facile solvent vapor annealing treatment. Macromol Mater Eng, 2018, 303: 1700489

58 Sepe A, Zhang J, Perlich J, et al. Toward an equilibrium structure in lamellar diblock copolymer thin films using solvent vapor annealing - An in-situ time-resolved GISAXS study. Eur Polymer J, 2016, 81: 607-620

59 Sinturel C, Vayer M, Morris M, et al. Solvent vapor annealing of block polymer thin films. Macromolecules, 2013, 46: 5399-5415

60 Chen L, Zhao K, Chi S, et al. Improving fiber alignment by increasing the planar conformation of isoindigo-based conjugated polymers. Mater Chem Front, 2017, 1: 286-293

61 Bauer AJP, Liu J, Windsor LJ, et al. Current development of collagen-based biomaterials for tissue repair and regeneration. Soft Mater, 2014, 12: 359-370

62 Gan Z, Jiang B, Zhang J. Poly( $\varepsilon$-caprolactone)/poly(ethylene oxide) diblock copolymer. I. Isothermal crystallization and melting behavior. J Appl Polym Sci, 1996, 59: 961-967

63 Zhou $\mathrm{C}, \mathrm{Chu} \mathrm{R}, \mathrm{Wu} \mathrm{R}$, et al. Electrospun polyethylene oxide/ cellulose nanocrystal composite nanofibrous mats with homogeneous and heterogeneous microstructures. Biomacromolecules, 2011, 12: 2617-2625

64 Hu C, Cui W. Hierarchical structure of electrospun composite fibers for long-term controlled drug release carriers. Adv Healthcare Mater, 2015, 1: 809-814

65 Lin J, Tian F, Shang Y, et al. Facile control of intra-fiber porosity and inter-fiber voids in electrospun fibers for selective adsorption. Nanoscale, 2012, 4: 5316-5320

66 Lai C, Guo Q, Wu XF, et al. Growth of carbon nanostructures on carbonized electrospun nanofibers with palladium nanoparticles. Nanotechnology, 2008, 19: 195303

67 Lu P, Xia Y. Maneuvering the internal porosity and surface morphology of electrospun polystyrene yarns by controlling the solvent and relative humidity. Langmuir, 2013, 29: 7070-7078

68 Guo R, Jiao T, Li R, et al. Sandwiched $\mathrm{Fe}_{3} \mathrm{O}_{4} /$ carboxylate graphene oxide nanostructures constructed by layer-by-layer assembly for highly efficient and magnetically recyclable dye removal. ACS Sustain Chem Eng, 2018, 6: 1279-1288

69 Liu Y, Hou C, Jiao T, et al. Self-assembled AgNP-containing nanocomposites constructed by electrospinning as efficient dye photocatalyst materials for wastewater treatment. Nanomaterials, 2018, 8: 35

70 Zhou J, Liu Y, Jiao T, et al. Preparation and enhanced structural integrity of electrospun poly( $\varepsilon$-caprolactone)-based fibers by freezing amorphous chains through thiol-ene click reaction. Colloids Surfs A-Physicochem Eng Aspects, 2018, 538: 7-13

71 Song J, Xing R, Jiao T, et al. Crystalline dipeptide nanobelts based on solid-solid phase transformation self-assembly and their polarization imaging of cells. ACS Appl Mater Interfaces, 2018, 10: 2368-2376

72 Huo S, Duan P, Jiao T, et al. Self-assembled luminescent quantum dots to generate full-color and white circularly polarized light. Angew Chem Int Ed, 2017, 56: 12174-12178

73 Zhou J, Gao F, Jiao $\mathrm{T}$, et al. Selective $\mathrm{Cu}(\mathrm{II})$ ion removal from wastewater via surface charged self-assembled polystyrene-Schiff base nanocomposites. Colloids Surfs A-Physicochem Eng Aspects, 2018, 545: 60-67

74 Luo X, Ma K, Jiao T, et al. Graphene oxide-polymer composite langmuir films constructed by interfacial thiol-ene photopolymerization. Nanoscale Res Lett, 2017, 12: 99

75 Sun S, Jiao T, Xing R, et al. Preparation of $\mathrm{MoS}_{2}$-based polydopamine-modified core-shell nanocomposites with elevated adsorption performances. RSC Adv, 2018, 8: 21644-21650

76 Li D, Wang Y, Xia Y. Electrospinning of polymeric and ceramic nanofibers as uniaxially aligned arrays. Nano Lett, 2003, 3: 11671171

77 Guibo Y, Qing Z, Yahong Z, et al. The electrospun polyamide 6 nanofiber membranes used as high efficiency filter materials: Filtration potential, thermal treatment, and their continuous production. J Appl Polym Sci, 2013, 128: 1061-1069

$78 \mathrm{Wu} \mathrm{H}$, Kong D, Ruan Z, et al. A transparent electrode based on a metal nanotrough network. Nat Nanotech, 2013, 8: 421-425

79 Zhang S, Liu H, Zuo F, et al. A controlled design of ripple-like polyamide- 6 nanofiber/nets membrane for high-efficiency air filter. Small, 2017, 13: 1603151

80 Vitchuli N, Shi Q, Nowak J, et al. Electrospun ultrathin nylon fibers for protective applications. J Appl Polym Sci, 2010, 116: 2181-2187

81 Wang N, Yang Y, Al-Deyab SS, et al. Ultra-light 3D nanofibre-nets binary structured nylon 6-polyacrylonitrile membranes for efficient filtration of fine particulate matter. J Mater Chem A, 2015, 3: 23946-23954

82 Wang N, Si Y, Wang N, et al. Multilevel structured polyacrylonitrile/silica nanofibrous membranes for high-performance air filtration. Separation Purification Tech, 2014, 126: 44-51

Acknowledgements This work was supported by the National Natural Science Foundation of China (21473153 and 51771162), Support Program for the Top Young Talents of Hebei Province, China Postdoctoral Science Foundation (2015M580214), Research Program of the College Science \& Technology of Hebei Province (ZD2018091), and the Scientific and Technological Research and Development Program of Qinhuangdao City (201701B004).

Author contributions Huang X, Jiao T, and Peng Q performed and designed the project and experiments. Liu Q, Zhang L, Zhou J, Li B, and Peng Q characterized the materials and discussed the results of the experiments. All the authors commented on the final paper.

Conflict of interest The authors declare no conflicts of interest. 

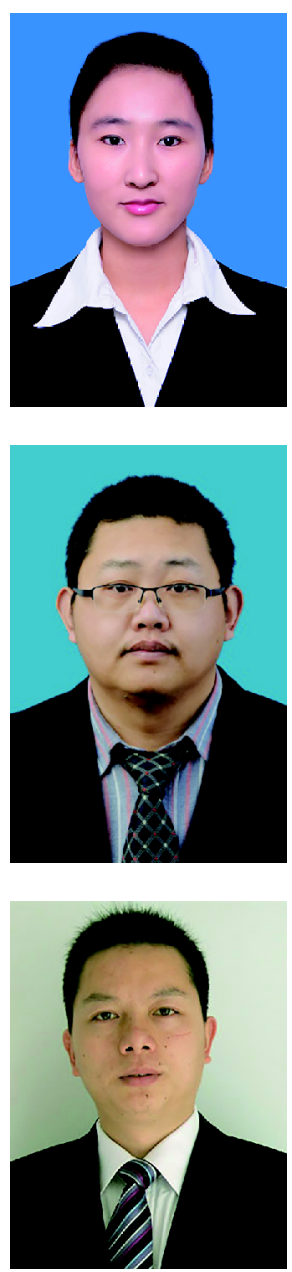

Xinxin Huang is a postgraduate student in Professor Jiao's group and will receive her master's degree from the School of Environmental and Chemical Engineering at Yanshan University in 2019. Her current research focus is electrospun nanofiber composite materials for PM2.5 capture applications.
Tifeng Jiao received his PhD degree in physical chemistry from the Institute of Chemistry, Chinese Academy of Sciences (CAS). He was a Postdoctoral Fellow at CNRS (Centre National de la Recherche Scientifique) with Prof. Girard-Egrot (Université Claude Bernard Lyon 1, Lyon, France). Currently, he is a Full Professor and Vice Director of the School of Environmental and Chemical Engineering, Yanshan University. His current research focus includes the synthesis of new self-assembled nanostructured materials and nanocomposites and their related properties.

Qiuming Peng received his BSc degree at Xiangtan University of Technology and his PhD degree in inorganic chemistry from Changchun Institute of Applied Chemistry, CAS. He was an Alexander von Humboldt Fellow with Prof. Karl Ulrich Kainer (GKSS, Germany). In 2011, he was appointed as a Professor at Yanshan University. His current research focus includes high-pressure metallic-based materials and their related mechanical and chemical properties.

\section{通过溶剂蒸汽处理制备多级静电纺丝纳米纤维作为空气过滤膜实现PM2.5高效捕获}

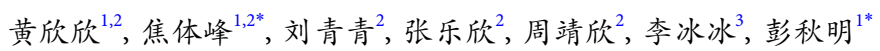

摘要 空气污染特别是颗粒物 $(\mathrm{PM})$ 污染, 已经威胁到人类的身体健康, 因而引起了全世界的高度关注. 人们在室外可通过口罩进行个人防 护, 然而一般的商业口罩起不到好的防护效果. 本文利用静电纺丝技术和溶剂蒸汽退火(SVA)方法制备了新型高效的聚 $(\varepsilon$-已内酯)/聚环氧 乙烷 (PCL/PEO)空气过滤纳米纤维. 通过SVA处理, 纤维表面变得褶皱, 增强了对PM2.5的捕获效率. 在重度污染状况(PM2.5颗粒浓度 $\left.>225 \mathrm{mg} \mathrm{m}^{-3}\right)$ 下, 这种纳米褶皱空气过滤膜的移除效率达 $80.01 \%$. 秦皇岛雾䨪天实地测量表明, 空气过滤膜能高效移除PM2.5. 与商业口 罩相比, 本文经过SVA处理后的PCL/PEO空气过滤膜具有制备方法简单、环境友好且易降解的特性, 在高效过滤膜领域有潜在应用. 